\title{
A Comparative Genre Analysis of English Business E-mails Written by Iranians and Native English Speakers
}

\author{
Saeed Mehrpour \\ Department of Foreign Languages \& Linguistics, Shiraz University, Shiraz, Iran \\ Mohaddeseh Mehrzad \\ Shiraz University Language Center, Shiraz, Iran
}

\begin{abstract}
The present study aimed at conducting a comparative genre analysis of English business e-mails at generic and lexico-grammatical levels. To this end, a corpus of 60 English business e-mails written by Iranians was compared with a counterpart corpus comprising the same number of emails written by the native English speakers. All of these e-mails served the same communicative purpose (i.e. providing and/or requesting information and actions). They were investigated following Swales (1990), Bhatia (1993) and Santos's (2002) notion of genre analysis. The results revealed that Iranian and native English business correspondents followed closely similar generic structures to exchange information. Moreover, Iranian correspondents favored the lexico-grammatical expressions that helped them respect their interlocutors' negative face whereas the native English speakers tried to encourage a friendly and intimate atmosphere. Investigating structures and characteristics of English language realized in business settings and for commercial purposes, this study offered a number of implications for business English teaching staff, material developers, and last but not least, business negotiators.
\end{abstract}

Index Terms - genre analysis, business e-mails, lexico-grammatical analysis, politeness

\section{INTRODUCTION}

As a type of Computer-mediated Communication (CMC), email is gradually replacing more traditional spoken and written modes, and becoming the dominant medium of communication all over the world. Owing to this growing inclination towards the use of emails, it became increasingly important to uncover the nature of this relatively new medium and the way it fulfills various communicative purposes in different discourse communities. To meet this end, researchers embarked upon the genre analysis of email in different contexts.

Genre analysis was first introduced by Swales (1990); as he asserted, the shared communicative purpose is the principal criterion that characterizes a class of communicative events as a genre. Each genre, according to Swales (1990) is composed of certain units called 'move'- "a discoursal and rhetorical unit that performs a coherent communicative function in a written or spoken discourse (Swales, 2004, p. 228)." Bhatia (1993), another pioneer in the realm of genre, believes that genre studies are beneficial to ESP students and teachers as they provide a pre-knowledge of formal and content schemata which would facilitate the learning of both generic conventions and the linguistic resources that help the realization of these conventions.

Drawing on Swales (1990) and Bhatia's (1993) notion of genre, several genre studies were conducted to identify the generic features of correspondences (i.e. letters and emails) (Abbasian and Tahririan, 2008; Al-Ali and Sahawneh, 2008; Barron, 2006; Cheung, 2006, 2007, 2008, 2009; Flowerdew \& Wan, 2006; Ho, 2009; Jalilifar \& Beitsayyah, 2011; Santos, 2002; Upton, 2002; Vergaro, 2002, 2004; to cite a few). However, most of these studies have dealt with the analysis of letters and only few have studied the structure of emails.

Santos (2002), for example, conducted a genre analysis of business letters; he examined a specific corpus of commercial letters called 'Business Letters of Negotiation' (LNs) in which all the letters served the purpose of providing and/or requesting information (and/or favors), or in other words, negotiating information. Finally, he extracted a four-move model and the common linguistic choices that were employed in order to realize each identified move. Santos (2002) believed that a large group of people can benefit from his study and get familiar with the linguistic features of such correspondences, since it has investigated a rather general communicative purpose.

Cheung (2009) conducted another genre study to compare the discourse structures of Chinese and English directmarketing sales e-mails and found that the two corpora share similar moves and steps. The results of this study revealed that the writers of sales mails determine the encoding of their messages according to their rhetorical goals, the viewermaker relationships they wish to establish through the texts, and the social and cultural context within which these texts unfold. In this process the sales genre is likely to adapt in terms of its discourse strategy and textual features. 
Barron (2006) presented a genre analysis of unsolicited promotional e-mails, i.e. 'spam'. The macro-textual analysis of 121 medical spam mails reveals that the unsolicited promotional e-mails undoubtedly belong to the promotional genre introduced by Bhatia (1993). The resulting move-scheme was found to be the product of a clearly persuasive communicative purpose and the specific rhetorical context in which spam mail functions.

Elucidating business genres, the above mentioned studies are worthy enough in today's commercial world as they offer practical implications to the business negotiators and the business teaching staff. However, as Santos (2002) contends, they are not sufficient because each study, in its own turn, presents only one aspect of the broad business world and analyzes one specific genre from a specific discourse community and therefore, much is still left to be investigated.

Genre analysis of Iranian correspondences has been rarely tackled. The dearth of research in this area could be attributed to the difficulty of access to the needed data (that is, letters and emails), or in other words, the difficulty of data collection. To the best of the researchers' knowledge, only three instances of research are devoted to the macrotextual analysis of the Iranians' letters and/or e-mails (Abbasian and Tahririan, 2008; Arvani, 2006; and Jalilifar \& Beitsayyah, 2011).

Arvani (2006) conducted a cross-cultural genre study of English business follow-up letters written by Iranians and native English speakers and found that the two sets of letters tended to share similarities in the patterns of moves and steps though subtle differences were found in the frequency of the moves applied. It was also revealed that both groups enjoyed nearly the same lexical density. And finally, Iranian business letters bore a few traces of politeness strategies of the English language.

Abbasian and Tahririan (2008) scrutinized emails that were exchanged between two different discourse communities: EFL teachers and biology professionals. The collected emails were contrasted following Santos' (2002) model of Business Letters of Negotiation (Abbasian and Tahririan, 2008). The results revealed that the same overall rhetorical structure was applicable to the two corpora. The two disciplines, nevertheless, show a degree of discrepancy in the strategies they used to realize each move. These observed differences in strategy use indicated the dynamic nature of email genre accommodating the rhetorical and functional needs of the discourse communities. Finally, Jalilifar \& Beitsayyah (2011) carried out a cross-linguistic genre analysis of Persian and English business letters and found a relative similarity in the generic structures of the two sets of letters and a considerable difference in the use of positive and negative politeness strategies.

All the three Iranian studies are informative enough since they adopted multi-perspective approaches for their analyses. Moreover, the cross-cultural and cross-linguistic comparisons could be quite pertinent to the current study and therefore, could inform the analysis here. Nevertheless, both Arvani (2006) and Jalilifar \& Beitsayyah (2011) examined a different medium of communication, i.e. letter. Moreover, Jalilifar \& Beitsayyah (2011) dealt with the Iranian correspondences which were written in the Persian language. And finally, Abbasian and Tahririan (2008) explored the use of English in an academic setting. As such, no study has yet analyzed English business emails that are written by the Iranian business negotiators. Consequently, another piece of research seems to be necessary since the medium of communication (i.e. letter, email, face to face speech, etc.), the language of use, and the discourse community in which the linguistic message has been generated can all affect the structure and configuration of an instance of language.

The present study, therefore, seeks to address the mentioned gap and conduct a comparative analysis of English business emails that are written by the Iranians and native English speakers. It can be a significant instance of research as it sheds light on a rather unknown mode of communication, i.e. email. Furthermore, as business has been globalized, the international language, i.e. English, is prevalently used as the medium of interaction by business negotiators around the world. Therefore, the comparison of the way different people with different language backgrounds adopt the English Language in their e-mails can yield helpful findings and can illuminate the extent to which the email messages are influenced by the interlingual and intercultural transfer. And, last but not least, the discourse community from which the data have been collected, i.e. the business correspondents, makes this research reasonably practical. With reference to studies of this kind, business negotiators can be trained in more effective rhetorical strategies and linguistic conventions which can better take forward their transactions with the native English speakers.

In order to address the afore-mentioned purposes, the following research questions are proposed:

1. Is there any difference between the macro structures of business e-mails written by Iranians and native English speakers?

2. Is there any significant difference between the typical lexico-grammatical features of English business e-mails written by Iranians and native English speakers?

\section{METHOD}

\section{A. The Corpus}

The corpus which was used for the present research consisted of business e-mails collected from companies in Iran and two English speaking countries, i.e. England and the United States. Through formal correspondence between Shiraz University officials and the business corporations, a set of English business e-mail messages written by the non-native Iranian (NNI) communicators were obtained from four companies in Shiraz, Iran and a company in Tehran. They were all well-established companies that usually had international transactions. Two business correspondents were graduate 
M.A. students of TEFL (teaching English as a Foreign Language) and one was a retired English teacher. Some other Iranian emails were also collected through a famous international trading website, i.e. alibaba.com. It is worth mentioning that not all of the companies with which we had correspondence were willing to give up their so-called confidential emails. Therefore, the researchers had to suffice to the collected emails and restrict their study to the companies. This set of e-mails was developed by 13 Iranian business correspondents.

Native English e-mails, on the other hand, were written by 21 native English-speaking (NE) communicators. A number of them were collected from a company in England which had transactions with a company in Shiraz. Some others were collected in the United States and forwarded by an Iranian business manager who lives there. And a few other emails were obtained using the online corpus of business emails, i.e. Enron Email Corpus which consisted of categorized emails that were written by the employees of the Enron Corporation in the U.S.

Since business e-mail is a broad category fulfilling various purposes, after conducting a preliminary analysis on the initial corpus of 500 e-mail messages, a homogeneous set of 120 e-mail messages (60 messages from each group) which served the purposes of 'providing and/or requesting information/actions/favors' were chosen for the main analysis. In order to preserve confidentiality, the e-address (or addresses) to which the message was sent (following To:) and the eaddress from which the message was sent (following From:) were changed. Three fake e-mail addresses were used instead of the real e-addresses: 1) Iran@gmail.co.ir; 2) England@gmail.co.uk; 3) United States@gmail.co.us. These unreal e-addresses showed the country of the origin (or, in some cases, the destination).

\section{B. Data Analysis Procedures}

The analytical procedures were divided into two major stages: macro-level analysis and micro-level analysis.

1. Macro-level analysis: Move analysis

In the present study, as mentioned above, genre analysis (Swales, 1990; Bhatia, 1993) formed the framework for the macro-textual analysis and the main communicative purpose guided the division of this genre into moves and steps. In order to determine the move-scheme and the strategies realizing each move, Santos's (2002) endeavor in genre analysis of Business Letters of Negotiation (LNs) constituted a model of reference to the present study. The reason underlying this choice is that the corpus used in the present study shares the same communicative purpose and discourse community as those investigated in Santos (2002). Moreover, Santos's (2002) model has been considered as a comprehensive and recent model (Abbasian \& Tahririan, 2008) and has been adopted in two Iranian studies (Abbasian \& Tahririan, 2008; Jalilifar \& Beitsayyah, 2011).

Therefore, the first analytical step was to examine the e-mail messages in order to identify the moves and steps present in the communicative event, as well as their frequencies and sequences. Once the move-schemes were extracted for each corpus and the frequency of each move/step was computed, Chi-square test was employed for each move and step separately in order to find out whether the differences between the parallel moves and steps in the two corpora were statistically significant.

In order to ensure the consistency and dependability of the utilized move-scheme and the results obtained from the generic analysis of the data, two types of reliability analysis, namely, inter-coder and intra-coder reliability were carried out and the results showed reliability coefficients of 0.91 and 0.94 , respectively.

2. Micro-level analysis: Lexico-grammatical analysis

A move has been defined as "a meaningful unit represented in linguistic (lexico-grammatical) forms and related to the communicative purposes of the activity in which members of the community are engaged" (Vergaro, 2002, p. 1214; 2004, p. 182). As implied in Vergaro's definition of move, each functional unit is realized through certain linguistic elements. Flowerdew and Wan (2006), too, believe that there are lexico-grammatical features typical to each move. In his study, Santos (2002) examined the most frequent linguistic realization of the moves.

Following the same trend, this study investigated the salient lexico-grammatical choices and strategies which characterize each identified move along with the reasons underlying such choices. Here again, Santos' (2002) study was adopted as a model of reference and features like the use of subject pronouns and the three grammatical structures (imperative, interrogative, and declarative), and the specific wordings and expressions used to realize each step were selected to be examined. The two corpora were compared with respect to these features and strategies so that the differences and similarities between the native English and the non-native Iranian business e-mails were uncovered.

\section{RESULTS AND DISCUSSION}

\section{A. The Generic Structure of Business E-mails}

The preliminary move-analysis of the two corpora revealed that a similar four-move scheme as that proposed by Santos (2002) was applicable and relevant to the data collected for the present study. Four obligatory moves as those found in Santos' study were identified in both corpora. These obligatory moves are as follows:

Move 1. Establishing the negotiation chain

Move 2. Providing information/answers

Move 3. Requesting information/action/service/favors

Move 4. Ending 
Although the same four moves were employed by both the native English and the non-native Iranians, the two corpora revealed a number of differences in the 'steps' which realized these moves. Figures 1 and 2 demonstrate the recurrent generic structures of non-native Iranian and native English business e-mails, respectively. As evident, where there is a difference in the step utilized, it is marked using an asterisk.

\begin{tabular}{|c|c|c|}
\hline \multicolumn{3}{|c|}{ MOVE 1} \\
\hline \multicolumn{3}{|c|}{ Establishing the negotiation chain } \\
\hline \multicolumn{3}{|c|}{ Steps } \\
\hline (i) & \multicolumn{2}{|l|}{ Defining participants } \\
\hline (a) & \multicolumn{2}{|l|}{ Sender- line } \\
\hline (b) & \multicolumn{2}{|l|}{ Recipient- line } \\
\hline (c) & \multicolumn{2}{|l|}{ Subject- line } \\
\hline (d) & \multicolumn{2}{|l|}{ Date- line } \\
\hline (e) & \multicolumn{2}{|l|}{ Attention to the message- line * } \\
\hline (ii) & \multicolumn{2}{|l|}{ Opening } \\
\hline (a) & \multicolumn{2}{|l|}{ Addressing and greeting the addressee } \\
\hline (b) & \multicolumn{2}{|l|}{ Thanking the addressee } \\
\hline (c) & \multirow{2}{*}{\multicolumn{2}{|c|}{$\begin{array}{l}\text { Apologizing* } \\
\text { Reference to previous contact }\end{array}$}} \\
\hline (iii) & & \\
\hline \multicolumn{3}{|c|}{ AND/OR } \\
\hline \multirow{2}{*}{\multicolumn{2}{|c|}{ MOVE 2}} & MOVE 3 \\
\hline \multirow{2}{*}{\multicolumn{2}{|c|}{$\begin{array}{l}\text { Providing } \\
\text { (Information/Answers) }\end{array}$}} & Requesting \\
\hline & & (Information/Action/Favor) \\
\hline \multicolumn{2}{|c|}{$\begin{array}{l}\text { (Intormation/Answers) } \\
\text { Steps }\end{array}$} & Steps \\
\hline (i) & Information & Information \\
\hline (a) & Introducing and providing information & Explaining/clarifying/requesting information \\
\hline (b) & Continuing/adding/up-dating & Exchanging/asking for ideas/opinions \\
\hline (c) & Agreeing/confirming information & Confirming information \\
\hline & Showing opposition (unexpected & \\
\hline \multicolumn{3}{|c|}{ results)/disagreeing } \\
\hline (ii) & Advising about message & Actions/favors of: \\
\hline (a) & Along with e-mail (attachment) & Material/document mailing \\
\hline (b) & Via link/website & Service/action \\
\hline \multicolumn{3}{|c|}{ STEPS COMMON TO BOTH MOVES $2 \& 3$} \\
\hline \multicolumn{3}{|c|}{ Negotiating } \\
\hline (iii) & \multicolumn{2}{|l|}{ Evaluating } \\
\hline (a) & \multicolumn{2}{|l|}{ Giving personal opinion } \\
\hline (b) & \multicolumn{2}{|l|}{ Making comments } \\
\hline (iv) & \multicolumn{2}{|l|}{ Drawing attention to something } \\
\hline (v) & Indicating wishes/plans/intentions & \\
\hline (vi) & Applying pressure tactics & \\
\hline MO & & \\
\hline Endi & & \\
\hline Step & & \\
\hline (i) & Prompting further contact: soliciting response* & \\
\hline (ii) & Signing-off & \\
\hline (iii) & Signature-line & \\
\hline (iv) & Job status in the company & \\
\hline (v) & Company name & \\
\hline (vi) & Contact information & \\
\hline (vii) & Note \& PS-line* & \\
\hline
\end{tabular}

Figure 1. The generic structure of non-native Iranian business e-mails 


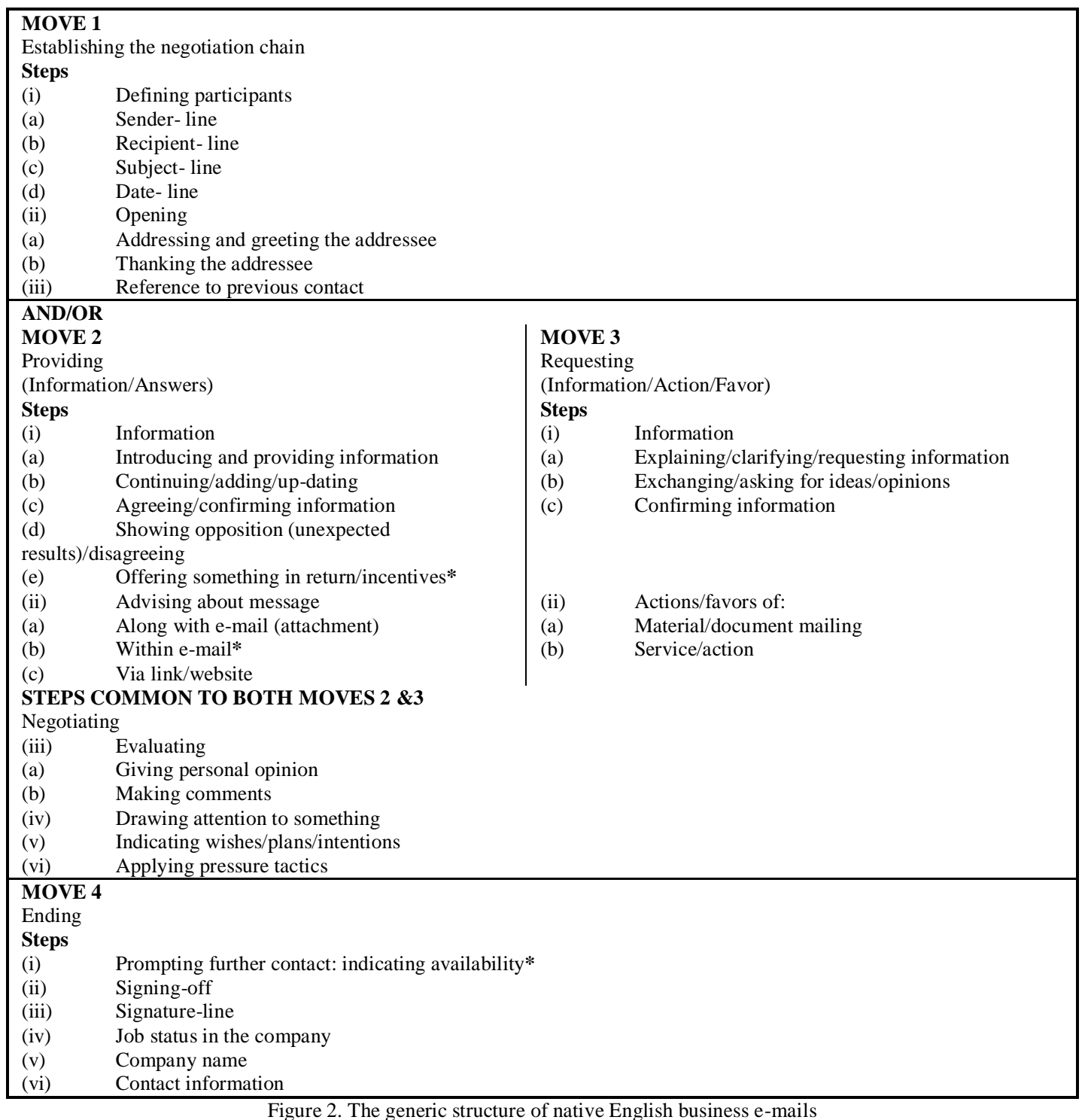

As shown in these figures, there are three steps which were found in the Iranian corpus but not in its English counterpart. These steps are as follows:

M-1 (i-e) Attention to message, which signals the importance of the message and therefore, encourages the e-mail recipient to take a prompt action;

M-1 (ii-c) Apologizing, which is employed in order to express regrets; and

M-4 (vi) Note \& PS-line, which is added as the last-minute information which deserved special attention and was therefore, highlighted.

On the other hand, two steps were utilized in the English corpus which were absent in the Iranian e-mails. These two steps are:

M-2 (i-e) Offering something in return, which compensates for a previous disagreement or opposition; and

M-2 (ii-b) Advising about the message within e-mail, which provides extra information within the e-mail itself.

There is another step which, though present in both corpora, is realized through different strategies by native English and non-native Iranian e-mail writers. The step Prompting Further Contact is carried out through the solicitation of response among the Iranians while it is accomplished by an indication of availability on the part of the Native English speakers.

Following, are some examples extracted from the two corpora. They both exemplify the application of the moveschemes on the emails and highlight the differences noticed between the two corpora. 
M1 (i-a)

(i-d)

(i-b)

(i-c)

(i-e)

M1 (ii-a)

M2.(i-d)

(iii-b)

M3. (ii-b)

(vi)

M2. (ii-a)

(vi)

M4 (ii)

(iii)

(iv)

(v)

(vi)

(i-a)

(i-b)

(ii-a)

$\left(\right.$ ii-c) ${ }^{*}$

(i) ${ }^{*}$

(iii)

(vi)

(vii)

M1 (i-a)

M1 (ii-a)

M2.(i-a)

(iii-b)

(ii-b)

M2.

(i-b)

(ii-a)

M4. (i)

(ii)

(ii)

[1]

Non-native Iranian e-mail sent to both provide information and request action From: Shiraz@gmail.co.ir

Sent: Wednesday, March 17, 2010 10:07 AM

To: 'Christian.Klima@Linde-LE.com'

Subject: RE: 2103-REQ-A-HM-251 Reformer Lordegan - Revised Technical Quotation

Importance: High

\section{TOP URGENT}

Dear sir

Unfortunately your recently submitted technical proposal for the above subject does not include all our requested replies to our last TQ and therefore the submitted technical proposal accounts to be poor for final evaluation. To speed up the work and in order to enhance Linde technical proposal in final evaluation, you are strongly requested to take prompt action and complete/submit the attached table which you received on previous Friday, latest by midday today. Your urgent action on the above is highly appreciated.

Yours Faithfully

Farshid Farshchi

EP Director

$\mathrm{X}$ Engineering Corporation

$* * * * * * * * \sim * *$ extension: 1358

$* * * * * * * * * * * *$

f.farshchi@X.org

\begin{tabular}{l}
$\qquad[2] \quad$ Non-native Iranian e-mail (Move 1) \\
\hline From: $\frac{\text { Shiraz@gmail.co.ir }}{\text { To: paul@edm.co.uk }}$ \\
Dear Mr. Denton, \\
Sorry for long answer due to religious holidays in Iran. \\
\hline
\end{tabular}

[3] Non-native Iranian e-mail (Move 4)

\section{Your fast reply will be appreciated.}

Thanks and Regards,

Mohmmad Kalani Tehrani

Mobile : ***********

Fax : ******** or $* * * * * * * *$

Tel : ******** or $* * * * * * * * *$

Kindly notice that, we have already been importing from China directly ( Electric Wire Rope Hoists from Xintai in Shandong, EDM Sink and Wircut and super drills from Jiangsu and Hydraulic mobile truck Cranes from XCMG from XUZHOU and agricultural tractors from Liang and distributing other machine tools imported by other Iranian Partners .

[4] Native English e-mail sent to provide information

From: United States@gmail.co.us.

Hello Daneile and Vicki,

At last we got the crack in the foundation repaired. They went out there, last week and it is all done. But what really helped was the work we did on the outside to divert the water away from the house. Here is what the tenants wrote to me:

Hi Sean!

Just wanted to send a note to let you know that the work you had done outside has really seemed to have done the job. All that rain we received the week they were supposed to come out and fix the basement and the bit of rain since then, and there's not a DROP of water in the bucket from any of that. Amazing!!! I believe they can probably come and fix it whenever. It seems that the outdoor work has done the job. Thought you might appreciate the update and maybe want to share with Vicki and Daniele. Have a good day and a Happy Thanksgiving. Carrie

This was before they finally went and did epoxy the crack. But it is all done.

Also attached is the financial statement.

Please let me know if you have any questions.

Thank you and have a wonderful Holiday.

Sean 
The following sections are devoted to the detailed discussion of each move where the differences and similarities between the native English and non-native Iranian business e-mails are singled out, the results of tests of significance are reported and interpreted, and the probable underlying reasons are pointed out.

1. Move 1: Establishing the negotiation chain

Occupying the header position in e-mails, Move 1 sets up the negotiation chain and introduces the communication scene (Santos, 2002). Within the current corpora, 63 occurrences of the first move were found in the native English corpus and 84 occurrences in the non-native one. These high frequencies signify the importance and commonality of this move across the two corpora. Though Move 1 appears to be more frequent in the Iranian corpus, a chi-square test of significance revealed that this difference is not significant $(\mathrm{df}=1$, ch-sq $=3, \mathrm{p}=.083)$.

In Move 1, the acts of greeting and thanking the addressee constituted the core. These two functions were carried out with relatively similar frequencies across the two corpora; the function of greeting was realized in 52 native and 60 nonnative emails, and the function of thanking appeared in 8 native and 17 nonnative emails. Test of significance also revealed no significant differences here ( $\mathrm{p}_{\text {Greeting }}=0.450 ; \mathrm{p}_{\text {Thanking the addressee }}=0.72$ ).

2. Move 2: Providing information/answers

Together with the third move, Move 2 - Providing information/answers - is responsible for the real content of the message (Santos, 2002). It displays one facet of the overall purpose which motivated the communication: the exchange of information. Occurring 100 times within the native English corpus and 85 times within the non-native Iranian one, this move seems to be an obligatory move within 'providing/requesting information' genre. Despite the observed difference in the frequency of occurrence, the results of a Chi-square test of significance showed that the two corpora were not meaningfully different with respect to this move $(\mathrm{p}=0.27)$.

The move Providing Information is accomplished through two main steps within both Iranian and English corpora. Each step comprises several sub-steps across the two corpora (see Figures 1 and 2). Table 4 below gives the frequencies of occurrence of each step and sub-step within the two corpora and summarizes the results of the Chi-Square tests of significance (Note: The Roman numerals shown in Table 1 corresponds to those represented in Figures 1 and 2 above).

TABLE 1.

FREQUENCIES AND CHI-SQUARE TESTS BETWEEN NATIVE AND NON-NATIVE E-MAILS FOR STEPS AND SUB-STEPS IN MOVE 2

\begin{tabular}{|c|c|c|c|c|c|c|c|c|c|}
\hline & & i-a & i-b & i-c & i-d & i-e & ii-a & ii-b & ii-c \\
\hline \multirow[t]{3}{*}{ Frequency } & Native & 47 & 24 & 2 & 3 & 2 & 15 & 6 & 1 \\
\hline & Nonnative & 47 & 17 & 4 & 7 & 0 & 8 & 0 & 1 \\
\hline & Total & 94 & 41 & 6 & 10 & 2 & 23 & 6 & 2 \\
\hline \multirow[t]{3}{*}{ Test Statistics } & Chi-Square & $.000^{\mathrm{a}}$ & $1.195^{\mathrm{a}}$ & & $1.600^{\mathrm{a}}$ & & $2.130^{\mathrm{a}}$ & & \\
\hline & Df & 1 & 1 & & 1 & & 1 & & \\
\hline & Asymp. Sig. & 1.000 & .274 & & .206 & & .144 & & \\
\hline
\end{tabular}

As seen in Table 1, there is no significant difference between the two corpora in terms of the steps and sub-steps of Move 2. (Note: Chi-square test was not run for Agreeing/Confirming Information, Offering Something in Return/Incentives, Advising about Message Within E-mail, and Advising about Message Via Link/Website sub-steps because they do not satisfy one of the main prerequisites of this statistical test; that is, no cell should have expected frequencies less than 5.)

\section{Move 3: Requesting information/action/favor}

As mentioned before, both Move 2 and Move 3 constitute the body of the e-mail and, therefore, incorporate the main propositional content of the message. The frequency of the third move was 66 in the non-native Iranian corpus and 50 in the native English one. Chi-Square test of significance revealed that the two corpora did not differ significantly in terms of the frequency of their requests $(\mathrm{p}=0.137)$.

Move 3 was realized via two main steps across the two corpora. Not only did both sets of e-mails adopt the same two steps, but they utilized identical sub-steps in order to carry out the third function (see Figures 1 and 2, above).

In spite of the close correspondence in the types of the steps and sub-steps employed, the two corpora showed a number of differences regarding the frequency with which each part is employed. Table 2 below summarizes the observed differences providing the frequency information. It also reports the results of the tests of significance run between the two corpora. (Note: Chi-square test was not conducted for Confirming Information sub-step as it does not satisfy the previously mentioned assumption of the Chi-square test.)

TABLE 2.

FREQUENCIES AND CHI-SQUARE TESTS BETWEEN NATIVE AND NON-NATIVE E-MAILS FOR STEPS AND SUB-STEPS IN MOVE 3

\begin{tabular}{lllllll}
\hline & & i-a & i-b & i-c & ii-a & ii-b \\
\hline Frequency & Native & 11 & 6 & 3 & 8 & 22 \\
& Non-native & 29 & 3 & 6 & 11 & 17 \\
& Total & 40 & 9 & 9 & 19 & 39 \\
\hline Test Statistics & Chi-Square & $8.100^{\mathrm{a}}$ & $1.000^{\mathrm{a}}$ & & $.474^{\mathrm{a}}$ & $.641^{\mathrm{a}}$ \\
& Df & 1 & 1 & & 1 & 1 \\
& Asymp. Sig. & $\mathbf{. 0 0 4}$ & .317 & & .491 & .423 \\
\hline
\end{tabular}


As Table 2 indicates, the native English business e-mails were significantly different from the non-native Iranian ones with respect to the first sub-step in Move 3. In other words, Iranian business persons asked for information, explanation and clarification significantly more than their English counterparts. The rest of the sub-steps; however, did not reveal any significant differences regarding their frequencies of occurrence within the two corpora.

4. Steps common to both moves 2 and 3

While moves 2 and 3 included a series of steps exclusive to each, there were certain steps which were shared by these two main moves (see Figures 1 and 2). As the name of the category Negotiating suggests, these steps brought the negotiation strategies into play and, therefore, enhanced the negotiation process. Iranian and English e-mail writers used the same sets of steps in order to promote their negotiation. These steps appeared with relatively similar frequencies (see Table 3) except for the step Applying Pressure Tactics which showed a significant difference across the two corpora $(p=0.028)$. It was significantly more frequent in the Iranian corpus. This business tradition could have resulted from the broader Iranian culture in which people are accustomed to persuade others to do things promptly by applying different pressure tactics.

TABLE 3.

FREQUENCIES AND CHI-SQUARE TESTS BETWEEN NATIVE AND NON-NATIVE E-MAILS FOR STEPS COMMON TO BOTH MOVES 2 AND 3

\begin{tabular}{lllllll}
\hline & & iii-a & iii-b & iv & v & vi \\
\hline \multirow{3}{*}{ Frequency } & Native & 7 & 6 & 3 & 9 & 9 \\
& Nonnative & 5 & 13 & 5 & 8 & 21 \\
& Total & 12 & 19 & 8 & 17 & 30 \\
\hline Test Statistics & Chi-Square & $.333^{\mathrm{a}}$ & $2.579^{\mathrm{a}}$ & & $.059^{\mathrm{a}}$ & $4.800^{\mathrm{a}}$ \\
& Df & 1 & 1 & & 1 & 1 \\
& Asymp. Sig. & .564 & .108 & & .808 & $\mathbf{. 0 2 8}^{*}$ \\
\hline
\end{tabular}

\section{Move 4: Ending}

Move 4 is the last move in business e-mails and signals the end of the message. This move was the most frequent move used in both Iranian and English corpora. With the total of 339, Move 4 occurred 137 times in the Native English corpus and 202 times in the non-native Iranian one. The test of significance revealed that the two corpora were meaningfully different with respect to this move. That is, Iranian business correspondents used this move significantly more than their English counterparts $(p=0.000)$. This difference was due to the inclusion of different information categorized under Move 4 by the Iranian writers in most of the e-mails, whereas the native English writers mostly tended to end up their e-mails with the most basic steps, i.e. sign-off and signature-line.

Like other moves, Move 4 was realized through special steps (see Figures 1 and 2 above) which appeared with different frequencies across the two corpora (see Table 4 below). As seen in Table 4, four steps were significantly different between the two corpora: Prompting Further Contact, Job Status in the Company, Company Name, and Contact Information. Prompting Further Contact, Job Status in the Company, and Company Name were more common in Iranian e-mails while Contact Information was more recurrent in English e-mails.

TABLE 4.

FREQUENCIES AND CHI-SQUARE TESTS BETWEEN NATIVE AND NON-NATIVE E-MAILS FOR STEPS IN MOVE 4

\begin{tabular}{|c|c|c|c|c|c|c|c|c|}
\hline & & $\mathrm{I}$ & ii & iii & Iv & $\mathrm{V}$ & vi & vii \\
\hline \multirow[t]{3}{*}{ Frequency } & native & 6 & 52 & 44 & 4 & 18 & 18 & 1 \\
\hline & nonnative & 15 & 59 & 56 & 39 & 39 & 8 & 0 \\
\hline & Total & 21 & 111 & 100 & 43 & 57 & 27 & 1 \\
\hline \multirow[t]{3}{*}{ Test Statistics } & Chi-Square & $3.857^{\mathrm{a}}$ & $.441^{\mathrm{a}}$ & $1.440^{\mathrm{a}}$ & $28.488^{\mathrm{a}}$ & $7.737^{\mathrm{a}}$ & $4.481^{\mathrm{a}}$ & \\
\hline & $\mathrm{df}$ & 1 & 1 & 1 & 1 & 1 & 1 & \\
\hline & Asymp. Sig. & $.050 *$ & .506 & .230 & $.000 *$ & $.005 *$ & $.034 *$ & \\
\hline
\end{tabular}

On the whole, what was inferred from the macro textual analysis is that non-native Iranian and native English business correspondents follow closely similar generic structures to accomplish their overall communicative goal, i.e. 'requesting and providing information'. As seen in the two move schemes that were applied by Iranian and native English speakers (see Figures 1 and 2) similarities outnumber differences: both corpora applied the same four obligatory moves; similar steps were used to realize these obligatory moves; and most of the moves and steps were employed with relatively similar frequencies across the two corpora. This result confirmed that of Arvani (2006) where it was concluded that NNI writers followed the prototypes of business writing used by NE writers.

\section{B. Lexico-grammatical Features of Business E-mails}

Beside generic structure, the most salient and typical lexico-grammatical choices and strategies characterizing moves 3 and 4, the main parts which were responsible for the propositional content of the e-mail message, were investigated and the two Iranian and English corpora were compared with reference to these features. The results of this analysis are presented in the following sections.

1. Lexico-grammatical features in Move 2

An in-depth analysis of the second move, Providing Information/Answers, showed that certain linguistic features helped the realization of this specific rhetorical function. The first finding was regarding the choice of participants. First 
person plural, we, was applied most commonly by the Iranians. The third parties they/proper names were also found to be rather prevalent within the Iranian business e-mails. The following examples extracted from the non-native corpus illustrate these lexical choices:

[5] We inform you that we arrange the shipment and payment ... (NNI-7)

[6] Then Mr. Ardi, Mr. Poujam, and Mr. Rabinejad will join them on Wednesday. (NNI-23)

On the other hand, as can be seen in the examples below, the first person singular, $I$, and words related to machines, products, and services were more common within the native English corpus.

[7] I will reduce the export price Down to $£ 22,000.00$ UK Pound for you...

[8] The transaction is for delivery of intrastate gas at the tailgate ... (NE-35).

The predominant use of we shows the Iranian business correspondents' tendency to focus on the company or the corporation as a whole -a frequent convention in Persian letter writing- and implies that the entire group, rather than the writer as an individual, is responsible for the provided information. This result is similar to that found in Jalilifar \& Beitsayyah (2011) and confirms the cross-linguistic effect the notion of 'transfer'. On the contrary, native English speakers' frequent use of $I$ indicates their "personalized professional attitude, i.e. the writer is focusing on him/herself and shifting the responsibility of the message from the company (Santos, 2002, p. 186)" and, in this way, confirms the results of Flowerdew and Wan's (2006) study.

The first step in Move 2, i.e. Introducing and Providing Information, is characterized by a specific lexicogrammatical unit within most of the Iranian e-mails. Iranian business correspondents adopt the word 'inform' or its noun form -information - to make the addressee aware of a new piece of information. The examples below illustrate this feature:

[9] We would like to inform you that our dealing is not selling ... (NNI-17)

[10] For your information, I am the sales manager of Lari company ... (NNI-54)

Though compatible with the communicative function of this step, i.e. providing information, the above structures only appeared in the non-native Iranian corpus and no instance was witnessed within native English e-mails. One reason underlying this finding can be the letter writing conventions in Persian. Using similar structures is quite conventional in Persian formal letter writing.

Similarly, the step Agreeing/Confirming Information is realized through specific lexical choices. These choices, however, are shared by the two corpora. The business correspondents participating in this study either used the lexical word 'accept' or 'confirm' to fulfill the act of agreement. Following are two authentic examples that occurred within the current data:

[11] Yes as we are doing ongoing business I accept your offer of $£ 21,000.00$ UK Pounds including full case packing. (NE-11)

[12] We confirm the shipping documents. (NNI-6)

Another lexical feature that occurred systematically across the two corpora was different forms of the word 'attach' which was employed to execute the function of advising about the message via attachment. There were no discrepancies between the two corpora regarding the adoption of this feature.

2. Lexico-grammatical features in Move 3

Requesting information, actions or favors can be accomplished through three different grammatical structures: imperative, interrogative, and declarative. Here, however, these three forms differ in terms of 'directness'. Using indirect speech acts to ask for a favor is considered more gentle and polite in English speaking communities than direct commands (Yule, 2006).

All these three forms were observed within both sets of data analyzed in the present study. In the Iranian corpus, imperative and declarative forms were both common, being used 36 and 24 times, respectively. Interrogatives, however, appeared only in few e-mails $(\mathrm{N}=6)$. In the native English corpus, too, imperatives were the most common $(\mathrm{N}=20)$. The other two forms were adopted with the same frequencies $(\mathrm{N}=15)$ and were both rather common. Therefore, there was not much discrepancy between the two corpora regarding the use of these three structures except for the interrogatives which was more common within the native data.

Nevertheless, Iranians seemed to favor certain lexico-grammatical expressions in order to minimize the imposition of their commands. It was quite interesting that these lexico-grammatical choices sometimes made the Iranians' requests sound more polite than those of the native speakers. Hereunder are some examples extracted from the Iranian corpus to exemplify these linguistic features:

[15] To begin with we would like to ask you the favour of giving us your prices... (NNI-47)

[16] Could you kindly send us the proforma invoice by return mail if the product... (NNI-50)

[17] Please give me the exact day and time of your arrival to Iran. (NNI-19)

As seen in the above examples, interrogatives and declaratives were usually mitigated by the modals could and would, or the expression would like. The use of these modals, according to Arvani (2006), adds to the indirectness of the act and therefore, makes it more polite and courteous. Direct imperatives are also preceded by the adjunct please which "strengthens the aspect of politeness and adds to the exchange an atmosphere of extreme formalism, respect and facesaving (Santos, 2002, p. 182)". In addition, the adverb kindly is often added to create an atmosphere of cordiality and geniality. 
English e-mails, on the other hand, seem to be more straight-forward regarding the execution of requests. Though the native English writers had applied the modals could and would in a number of e-mails, they more tended to ask for a favor using the less formal modal, can. Furthermore, no instance of the adverb kindly was observed in this group of emails. These differences may have been caused by a socio-cultural reason. Iranians, who may be regarded as following the value of collectivism, show a lot of concern about the addressee's negative face and try to respect it by any possible means. On the contrary, English people are more friendly, intimate and casual, and do not worry about such bothersome conventions.

3. Lexico-grammatical features in steps shared by Moves 2 and 3

The common steps, by which the negotiation strategies were brought into play, incorporated certain lexicogrammatical features which helped the fulfillment of the intended functions. To begin with, the first Evaluating sub-step i.e. Giving Personal Opinion, was mainly characterized by the pronoun $I$ and, in a few cases, specific markers that indicated the writer's personal attitude. The examples below briefly illustrate these options.

[18] I as one your friends suggest you to study the relationship between yours and his one more again. (NNI-8)

[19] It would be easier for me if we be in touch via E-mails. (NNI-54)

[20] If the group feels it would be helpful to meet to discuss the timeline issues, I am in support of that effort. (NE-49)

On the other hand, the pronouns we and you were used in order to make comments and give opinions which were shared by a group (the company members rather than the individual him/herself) (examples 26 and 27 below).

[21] It certainly appears you have lined up a most impressive program and an outstanding group of speakers. (NE57)

[22] If you find the machine in a good condition, we trust you as before. Just we should agree on its price. (NNI-1)

As seen in the above examples, these two sub-steps drew upon certain lexical options, such as trust, believe, and eager, which contain emotional connotations and therefore, conveyed thoughts, feelings and viewpoints. The next step, Drawing Attention, is realized through a number of emphatic linguistic choices (note, necessary, etc.) or a paralinguistic option, i.e. capitalization. Here are examples drawn from the two corpora:

[23] Considering the project procedure, kindly note that the PO should also be stamped by you. (NNI36)

[24] So a PRICE break down of each of the above mentioned components is needed, so that we order in our first shipment. (NNI-42)

[25] Please note the deadline to RSVP has been extended to 7/11/01, due to the July 4th holiday. (NE-26)

[26] Please keep in mind this is a necessary step in being able to control all our costs and report them accurately. (NE-55)

The two groups of participants also employed similar strategies to indicate their wishes, plans, or intentions. As suggested by the name of this step, the verbs hope, wish, intend, plan, and the expression look forward to were mostly used to carry out this function (see examples 27 and 28).

[27] I hope our friendship would continue. I hope the best for you and for your company. I wish I could visit you very soon in Iran and in my company. (NNI-17)

[28] We are planning to send the following e-mail to each of the desk heads. It is intended primarily to generate feedback from the desks, but my ultimate plan is to shut down the relationships and essentially start over with the desks making the transaction decisions instead of EOL. (NE-39)

Finally, in order to expedite the counterpart's decision and action, both Iranian and English e-mail writers used a number of pressure tactics which were realized either through similar linguistic expressions, such as prompt action, as soon as possible (or its abbreviated form A.S.A.P.), and at the earliest (refer to examples 29 and 30) or longer stretches of language as can be seen in example 31 .

[29] If you have done so already, can you please return your feedback to me ASAP? (NE-48)

[30] Your prompt response is highly appreciated. (NNI-20)

[31] As your competitors have already finalized all their technical issues recently, you are notified that unless we receive your reply until Wednesday 14th.April.2010, review of your technical quotation will be stopped and consequently it will be assumed you are not eager to take part in the competition. (NNI-40)

On the whole, what was inferred from the observations made through the lexico-grammatical analysis was the more use of the 'face-saving acts' on the part of the Iranians and their adherence to negative politeness strategies, contrary to the native English speakers' preference for positive politeness strategies and their attempt in promoting a cordial atmosphere. As Yarmohammadi (1995) concluded "in general the use of polite expressions are mostly negative and less positive in Persian in comparison with those of English" (p. 150). Writing English business e-mails, Iranians occasionally drew upon some of their native language conventions, specifically those which made their style more formal and polite and helped the maintenance of a reasonable distance with their interlocutors.

\section{CONCLUSIONS AND IMPLICATIONS}

As indicated before, the macro-level analysis of business e-mails brought about characterizations of the generic structures of these e-mails as written by the native English and the non-native Iranian business persons. Despite the presence of particular features peculiar to each corpus, the two corpora employed closely similar generic structures to fulfill the overall communicative goal, i.e. 'requesting and providing information'. Not only did they apply the same four 
obligatory moves, but they exploited similar steps, with relatively similar frequencies, to realize these moves. Therefore, the generic similarities exceeded the differences.

From among various reasons underlying this prevailing generic similarity (reasons like familiarity of the business negotiators with business transactions and English language through business manuals or internet), the common communicative purpose can be regarded as the prominent stimuli which gave rise to analogous schematic structures. These results, therefore, substantiated a genre-based hypothesis in which the communicative objective has been perceived to play the primary role in shaping a specific genre and, approved the findings of the previous studies done in this field (Vergaro, 2002; Arvani 2006; Cheung 2006, 2008, 2009; Abbasian and Tahririan, 2008).

Nonetheless, it should be noted that few differences were observed in the generic options adopted by the nativeEnglish and non-native Iranians. For instance, the steps Attention to message, Apologizing, Note \& PS-line, Offering Something in Return, and Advising about the Message within E-mail were either utilized by the native correspondents or the non-native ones, and were not shared by both groups. Some of these differences were caused by the linguistic phenomenon 'transfer' and revealed the impact of cultural variables on the configuration of information and ideas within e-mails (Abbasian and Tahririan, 2008; Flowerdew and Wan, 2006). Iranian business persons, for example, drew upon pressure tactics far more than their native English counterparts - an observation which reflected Iranians' native social and cultural traits.

A number of differences were also found at the lexico-grammatical level between the Iranian and native English corpora. These differences revealed that business transactions are influenced by broader socio-cultural variables. Typical of a culture where collectivism is highly valued, Iranian business correspondences were developed in a cautious way respecting the negative face of the corresponding businessmen. On the contrary, the native English business correspondents seemed to favor individualism and for this reason, applied strategies that did not bound their individual being.

The present study purported to make a small contribution to the research into the structures and characteristics of English language as realized in business settings. Consequently, it can offer a number of implications for business English teaching staff, material developers, and last but not least, business negotiators. Drawing on the results of the genre studies of this kind, EFL/ESP teachers can raise their students' awareness of e-mail message conventions. Furthermore, the results obtained here can inform and update business English courses so that business professionals are familiarized with the patterns which promote their conformity to the linguistic and pragmatic conventions of native English speakers and structures that might hinder their communication or even threaten their commercial ends.

It should be mentioned that the corpus gathered for the present study bore a drawback. Only 66 e-mails constituted mutual interaction of Iranian and native English speakers. As factors like social distance or status relationship can affect the nature of any interactions, the relevant data could have been gathered in a way to counterweigh such effects and yield more dependable results. To this end, it would have been more reliable to collect Iranians and native English speakers' mutual e-mails. Nevertheless, the collection of such a corpus was a quite challenging task. Business e-mails are usually very confidential and for this reason, companies are rather reluctant in providing researchers with their email messages. Therefore, the availability sampling had to be adopted here. Accordingly, future studies can compensate for the shortcomings of the present study and analyze structure of the emails taking the email addressees and their social status into account.

\section{REFERENCES}

[1] Abbasian, F., \& Tahririan, M. H. (2008). The discoursal and formal analysis of e-mails: A cross disciplinary genre analysis. Iranian Journal of Applied Linguistics (IJAL), 11(2), 1-22.

[2] Al-Ali, M. N., \& Sahawneh, M. B. (2008). An investigation into the generic features of English requestive e-mail messages. LSP \& Professional Communication, 8, 2(16), 40-64.

[3] Arvani, M. (2006). A discourse analysis of business letters written by Iranians \& native speakers. The Asian ESP Journal, 1 , 12-23.

[4] Barron, A. (2006). Understanding spam: a macro-textual analysis. Journal of Pragmatics, 38, 880-904.

[5] Bhatia, V. K. (1993). Analyzing genre: Language use in professional settings. London: Longman.

[6] Cheung, M. (2006). New media and sales promotion discourse: Implications on social strategy of credibility enhancement and persuasion. Paper presented at the annual meeting of the International Communication Association, Dresden International Congress Centre, Dresden, Germany Online <APPLICATION/PDF>. Retrieved 2009-05-25 from http://www.allacademic.com/meta/p90461_index.html.

[7] Cheung, M. (2007). Chinese and English sales discourse: A comparative study in Hong Kong. Paper presented at the annual meeting of the International Communication Association, TBA, San Francisco, CA Online <APPLICATION/PDF>. Retrieved 2010-06-04 from http://www.allacademic.com/meta/p172008_index.html.

[8] Cheung, M. (2008). 'Click Here': The impact of new media on the encoding of persuasive messages in direct marketing. Paper presented at the annual meeting of the International Communication Association, TBA, Montreal, Quebec, Canada Online <APPLICATION/PDF>. Retrieved 2010-11-05 from http://www.allacademic.com/meta/p232914_index.html.

[9] Cheung, M. (2009). The globalization and localization of persuasive marketing communication: a cross-linguistic socio-cultural analysis. Journal of Pragmatics, 42, 354-376.

[10] Flowerdew, J. \& Wan, A. (2006). Genre analysis of tax computation letters: how and why tax accountants write the way they do. English for Specific Purposes, 25, 133-153. 
[11] Ho, V. (2009). The generic structure and discourse strategies employed in downward request e-mail. The Linguistics Journal, 4 , $1,46-66$.

[12] Jalilifar, A. R., \& Beitsayyah, L. (2011). Genre Analysis of Enquiry Letters across Cultures: Perspectives on Rhetorical Structures. Concentric: Studies in Linguistics, 37(1), 309-333.

[13] Pinto dos Santos, V. B. M. (2002). Genre analysis of business letters of negotiation. English for specific purposes, 21, $167-199$.

[14] Swales, M. J. (1990). Genre analysis: English in academic and research settings. Cambridge: Cambridge University Press.

[15] Swales, M. J. (2004). Research genres: Explorations and applications. New York: Cambridge University Press.

[16] Upton, T. A. (2002). Understanding direct mail letters as a genre. International Journal of Corpus Linguistics. 7, 1, 65-85.

[17] Vergaro, C. (2002). "Dear Sirs, what would you do if you were in our position?'. Discourse strategies in Italian and English money chasing letters. Journal of Pragmatics, 34, 1211-1233.

[18] Vergaro, C. (2004). Discourse strategies of Italian and English sales promotion letters. English for Specific Purposes, 23, 181207.

[19] Yarmohammadi, L. (1995). More on the analysis of politeness forms in English and Persian: A sociopragmatic approach. IJOAL, 21, 57-67.

[20] Yule, G. (2006). The study of language. The United Kingdom: Cambridge University Press.

Saeed Mehrpour is assistant professor of TEFL at the Department of Foreign Languages and Linguistics of Shiraz University, Iran. He teaches BA, MA, and Ph.D. courses. His research interests include discourse analysis, sociolinguistics, language skills (especially, reading and listening comprehension) and language subskills (especially, vocabulary and pronunciation).

Mohaddeseh Mehrzad holds an MA in TEFL from the Department of Foreign Languages and Linguistics of Shiraz University, Iran. She currently teaches English at Shiraz University Language Center and Navid Language Institute in Shiraz. She is interested in conducting research in discourse analysis. 